\title{
Bockenheimer disease is associated with a TEK variant
}

\author{
Christopher L. Sudduth, ${ }^{1}$ Dennis J. Konczyk, ${ }^{1}$ Patrick J. Smits, ${ }^{1}$ Whitney Eng, ${ }^{2}$ \\ Alyaa Al-Ibraheemi, ${ }^{3}$ Joseph Upton, ${ }^{4}$ and Arin K. Greene ${ }^{1}$ \\ ${ }^{1}$ Department of Plastic and Oral Surgery, ${ }^{2}$ Division of Hematology and Oncology, ${ }^{3}$ Department of Pathology، \\ Boston Children's Hospital, Harvard Medical School, Boston, Massachusetts 02115, USA; ${ }^{4}$ Department of \\ Plastic Surgery, Boston Shriners Hospital, Boston, Massachusetts 02114, USA
}

\begin{abstract}
Bockenheimer disease is a venous malformation involving all tissues of an extremity. Patients have significant morbidity, and treatment is palliative. The purpose of this study was to identify the cause of Bockenheimer disease to develop pharmacotherapy for the condition. Paraffin-embedded tissue from nine individuals with Bockenheimer disease obtained during a clinically indicated operation underwent DNA extraction. Droplet digital polymerase chain reaction (ddPCR) was used to screen for variants most commonly associated with sporadic venous malformations (TEK [NM_000459.5:c.2740C > T; p.Leu914Phe], PIK3CA [NM_006218.4:c.1624G > A; p.Glu542Lys and NM_006218.4:c.3140A > G; p.His1047Arg]). ddPCR detected a TEK L914F variant in all nine patients (variant allele fraction 2\%-13\%). PIK3CA E542K and H1047R variants were not identified in the specimens. Sanger sequencing and restriction enzyme digestion confirmed variants identified by ddPCR. A pathogenic variant in the endothelial cell tyrosine kinase receptor TEK is associated with Bockenheimer disease. Pharmacotherapy targeting the TEK signaling pathway might benefit patients with the condition.
\end{abstract}

Corresponding author: Arin.greene@childrens.harvard .edu

(c) 2021 Sudduth et al. This article is distributed under the terms of the Creative Commons Attribution-NonCommercial License, which permits reuse and redistribution, except for commercial purposes, provided that the original author and source are credited.

Ontology term: venous malformation

Published by Cold Spring Harbor Laboratory Press

doi:10.1101/mcs.a006119

\section{INTRODUCTION}

Bockenheimer disease is an eponym describing a venous malformation (VM) involving most of the length of an extremity with all tissue planes affected (i.e., skin, subcutis, muscle, bone) (Kubiena et al. 2006). The condition is progressive and causes significant morbidity: pain, swelling, discoloration, phlebitis, ulceration, bleeding, joint stiffness, localized intravascular coagulopathy (LIC), pathologic fractures, and loss of function (Ali et al. 2020). Treatment includes compression, anticoagulants, sclerotherapy, and/or resection; amputation may be necessary. Bockenheimer disease is a sporadic condition, and its cause is unknown. The purpose of this study was to identify the etiology of Bockenheimer disease to develop improved treatments for patients. We hypothesized that because somatic activating variants in TEK and PIK3CA most commonly cause sporadic VMs, variants in these genes might also be responsible for Bockenheimer disease (Limaye et al. 2009, 2015).

\section{RESULTS}

Nine individuals with Bockenheimer disease of their arm or leg who underwent surgical excision were identified based on history, physical examination, and magnetic resonance (MR) imaging (Table 1; Fig. 1). The cohort included six females and three males. The disease 


\begin{tabular}{lcllr}
\hline \multicolumn{4}{l}{ Table 1. Bockenheimer disease cohort with a somatic } & TEK (NM_000459.5:c.2740C > T; p.Leu914Phe) variant \\
\hline Patient & Age at resection & Sex & Location & VAF (\%) \\
\hline 1 & 3 & Female & Left leg & 7.8 \\
2 & 9 & Female & Left arm & 8.8 \\
3 & 10 & Male & Left arm & 10.1 \\
4 & 13 & Female & Right arm & 12.8 \\
5 & 18 & Male & Right arm & 13.2 \\
6 & 20 & Female & Left leg & 2.0 \\
7 & 21 & Male & Right arm & 10.3 \\
8 & 38 & Female & Left arm & 12.2 \\
9 & 46 & Female & Right arm & 6.2 \\
\hline
\end{tabular}

(VAF) Variant allele frequency.

affected the right arm $(n=4)$, left arm $(n=3)$, or left leg $(n=2)$. Droplet digital polymerase chain reaction (ddPCR) identified a TEK L914F variant (NM_000459.5:c.2740C > T) in all nine individuals (Table 2). The variant allele frequency (VAF) ranged from $2 \%$ to $13 \%$. None of the tissue specimens contained either of the two PIK3CA variants that were tested. Patients 4, 5, and 8 with the highest VAFs had the TEK L914F variant confirmed with HpyAV digestion. The TEK L914F variant also was confirmed in Patient 5 by Sanger sequencing.

\section{DISCUSSION}

In 1907 Phillip Bockenheimer reported an adult male who had progressive upper extremity enlargement with dilated veins, ulceration, pain, and loss of function (Kubiena et al. 2006). Bockenheimer noted ectasia of all veins and that the bones were involved; he named the condition "genuine (congenital) diffuse phlebectasia" (Kubiena et al. 2006). Since the biological classification of vascular anomalies was established in 1982 (Mulliken and Glowacki 1982), the patient described by Bockenheimer was recognized to have a VM. The
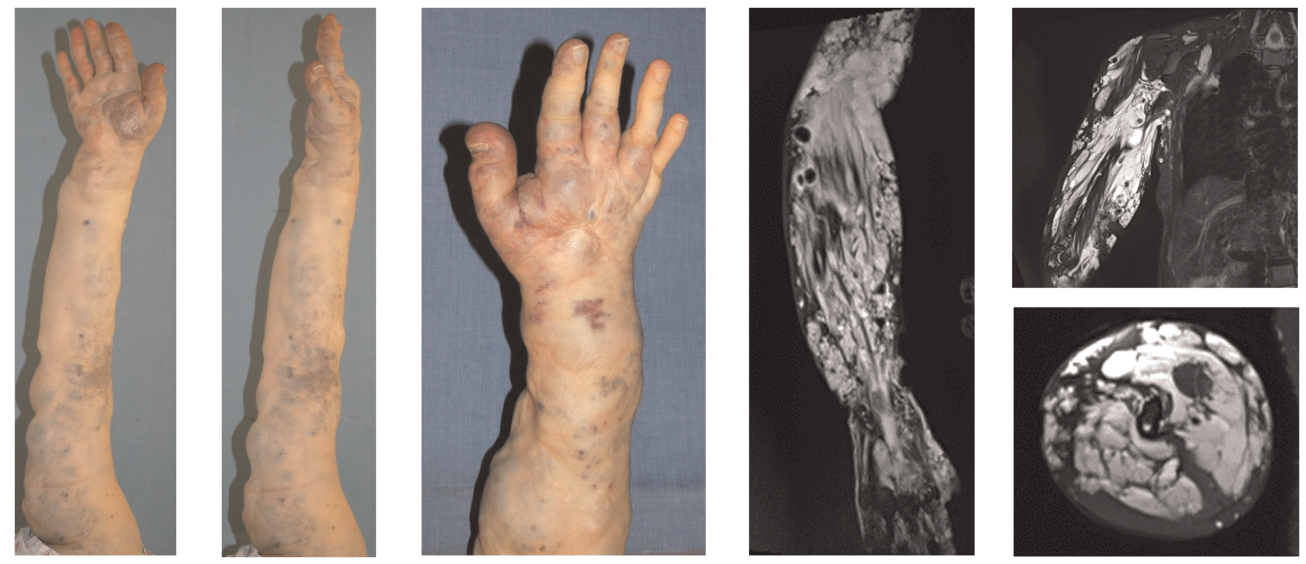

Figure 1. Adult female with Bockenheimer disease of the right arm (Patient 9). The patient has a diffuse venous malformation affecting the entire limb; magnetic resonance images show that all tissue planes are affected. Resected affected tissue contained a somatic TEK (NM_000459.5:c.2740C > T; p.Leu914Phe) variant (variant allele frequency [VAF] 6.2\%). 


\begin{tabular}{|c|c|c|c|c|c|c|}
\hline Gene & Genomic location & HGVS cDNA & $\begin{array}{l}\text { HGVS } \\
\text { protein }\end{array}$ & Zygosity & $\begin{array}{l}\text { Parent of } \\
\text { origin }\end{array}$ & $\begin{array}{c}\text { Variant } \\
\text { interpretation }\end{array}$ \\
\hline TEK & $\begin{array}{c}\text { Chr 9: } 27212760 \\
\text { (GRCh38) }\end{array}$ & $\begin{array}{c}\text { NM_000459.5:c.2740C > } \\
T\end{array}$ & p.Leu914Phe & $\begin{array}{c}\text { Somatic } \\
\text { heterozygous }\end{array}$ & N/A & Pathogenic \\
\hline
\end{tabular}

Bockenheimer eponym has been used to describe a VM that (1) affects most of the length of an extremity and (2) extends from the skin to the bone (Kubiena et al. 2006; Ali et al. 2020). Bockenheimer disease is recognized by the National Institutes of Health in the ClinVar database and by the European Union in the Ontology Lookup Service (MONDO_0016311).

VM TEK variants are associated with distinct phenotypes. We believe it is important to continue to use the Bockenheimer eponym because it describes a unique condition that facilitates communication and patient management. A germline TEK variant (NM_000459.4: c.2545C > T; p.Arg849Trp) causes cutaneomucosal VMs (Vikkula et al. 1996). Blue rubber bleb nevus syndrome (multifocal VMs of the skin, soft tissue, and gastrointestinal tract) results from somatic TEK variants occurring in cis (NM_000459.5:c.3314C > A; 3316A > C; p.Thr1105Asn;Thr1106Pro and NM_000459.4:c.2690A > T; 2744G > T; p.Tyr897Phe; Arg915Leu) (Soblet et al. 2017). The most common VMs are somatic, localized, and unifocal: These VMs with a TEK (L914F) variant typically affect the skin, whereas lesions containing a PIK3CA variant usually are subcutaneous (Limaye et al. 2009, 2015). The extent of the VM does not correlate with its VAF (Limaye et al. 2009), similar to our finding that Bockenheimer disease can result from a wide range of VAFs.

TEK is an endothelial cell tyrosine kinase receptor for vascular growth factors responsible for angiogenesis and vasculogenesis (Limaye et al. 2009). TEK variants affect the cytoplasmic kinase domain of the receptor. R849W blocks phosphatase activity preventing the kinase from being turned off, whereas L914F constitutively increases phosphorylation in the absence of ligand activation (Limaye et al. 2009; Du et al. 2017). TEK variants cause endothelial cells to grow in an abnormal pattern. Instead of a cobblestone monolayer, cells are elongated, overlap, and have decreased extracellular fibronectin (Nätynki et al. 2015). It is possible that the TEK L914F variant occurred earlier during embryogenesis or in a multipotent cell type to cause Bockenheimer disease compared to localized VMs. The TEK variant also may predispose cells to develop a second hit causing the Bockenheimer phenotype (Dekeuleneer et al. 2020). This possibility could be determined by searching the tissue for different TEK variants as well as variants in other genes involved in vascular signaling.

Patients with Bockenheimer disease typically have significant morbidity because the VM is extensive. Sclerotherapy and resection usually are only able to target the most problematic areas, such as localized sites of pain. Unfortunately, recurrence and progression of symptoms are common. Off-label use of sirolimus, an inhibitor of mTOR in the PIK3CA signaling pathway, has demonstrated efficacy in animal models and patients with VMs (Boscolo et al. 2015; Salloum et al. 2016; Hammer et al. 2018). Because we now know that Bockenheimer disease is associated with a pathologic TEK variant, patients may be candidates for sirolimus or other targeted therapies affecting TEK signaling.

\section{METHODS}

Our Vascular Anomalies Center database was searched for patients diagnosed with Bockenheimer disease who underwent a clinically indicated operative procedure of the limb. Formalin-fixed paraffin-embedded (FFPE) scrolls were obtained from the Department 
of Pathology. DNA was extracted using the Agencourt FormaPure DNA kit (Beckman Coulter). Patient-matched control tissue was unavailable. Variants in genes most frequently associated with sporadic VMs were screened using ddPCR: (1) TEK (NM_000459.5: c.2740C > T; p.Leu914Phe), (2) PIK3CA (NM_006218.4:c.1624G > A; p.Glu542Lys), and (3) PIK3CA (NM_006218.4:c.3140A > G; p.His1047Arg) (Limaye et al. 2009, 2015). A VAF > $1.0 \%$ was considered a true positive. Variants identified by ddPCR were confirmed with Sanger sequencing in one patient. Because the TEK variant disrupts a restriction site for the enzyme HpyAV (New England BioLabs), PCR fragments for three patients were digested with HpyAV as another method to confirm the presence of the TEK variant: (forward primer [FP]: 5'-GCCCCATGGAAATCTTCTGGAC-3'; reverse primer [RP]: 5'-CAGCGAAGTGA AGGAGCTGCTG-3'. The FP was designed to mutate a second HpyAV site, 13 bp upstream from the TEK variant (CCTTC to TCTTC). Digestion of the resulting 123-bp PCR fragment with HpyAV results in 35- and 88-bp fragments for a wild-type PCR fragment, whereas a PCR fragment containing the TEK variant will not be cut.

PCR primers and fluorescent probes for detecting wild-type (WT) and mutant TEK L914F alleles were designed: (1) FP 5'-TACGCGCCCCATGGAAACCT-3', (2) RP 5'-ACAGT GTGGACGGGGTGCTA-3', (3) WT probe 5'-5HEX/ACTTCCTTCGCAAGAGCCGTGT/-3', (4) mutant probe 5'-/56-FAM/TTCTTTCGCAAGAGCCGTGTG/-3'. PIK3CA E542K primers and probes included (1) FP 5'-CAGCTCAAAGCAATTTCTAC-3', (2) RP 5'-CACTTACC TGTGACTCCAT-3', (3) WT probe 5'-/5HEX/CTGAAATCA/ZEN/CTGAGCAGGAGA/-3', (4) mutant probe 5'-/56-FAM/CTAAAATCA/ZEN/CTGAGCAGGAG/-3'. PIK3CA H1047R primers and probes were (1) FP 5'-AACTGAGCAAGAGGCTTTGG-3', (2) RP 5'-TGTGTG GAAGATCCAATCCA-3', (3) WT probe 5'-5HEX/TGCACATCA/ZEN/TGGTGGCTGGA/-3', (4) mutant probe5'-/56-FAM/TGATGCACG/ZEN/TCATGGTGGCT/-3'. For each ddPCR reaction we used $45 \mathrm{ng}$ of template DNA. ddPCR was performed with a QX200 Droplet Generator, QX200 Droplet Reader, and QuantaSoft Software (Bio-Rad).

\section{ADDITIONAL INFORMATION}

\section{Data Deposition and Access}

The generated data set was deposited to ClinVar (https://www.ncbi.nlm.nih.gov/clinvar/) under accession number SCV001739510.

\section{Ethics Statement}

The Committee on Clinical Investigation at Boston Children's Hospital approved this study. All procedures performed were in accordance with the ethical standards of the institutional and national research committee and with the 1964 Helsinki Declaration and its later amendments or comparable ethical standards.

\section{Acknowledgments}

The authors acknowledge Steven Hann, PhD, Department of Orthopedic Surgery at Boston Children's Hospital, for assistance with designing ddPCR probes.

\section{Author Contributions}

C.L.S., D.J.K., and P.J.S. curated the data, administered and visualized the project, provided software, reviewed and edited the manuscript, and performed formal analysis, methodology, validation, and investigation. W.E. curated the data, administered and visualized the project, provided software, reviewed and edited the manuscript, and performed 
Competing Interest Statement

The authors have declared no competing interest.

Received June 27, 2021; accepted in revised form September 17, 2021. conceptualization, formal analysis, methodology, validation, and investigation. A.A.-I. curated the data, provided software, visualized the project, reviewed and edited the manuscript, and performed formal analysis, methodology, and validation. J.U. curated the data, visualized, supervised, and validated the project, reviewed and edited the manuscript, and provided resources. A.K.G. curated the data, administered and visualized the project, provided software, wrote the original draft and reviewed and edited the manuscript, provided resources, acquired funding, and performed conceptualization, formal analysis, methodology, supervision, validation, and investigation.

\section{Funding}

W.E. was supported by the Agency for Healthcare Research and Quality (AHRQ) grant number T32HS000063 as part of the Harvard Pediatric Health Services Research Fellowship Program.

\section{REFERENCES}

Ali B, Panossian A, Taghinia A, Mulliken JB, Alomari A, Adams DM, Fishman SJ, Upton J. 2020. Diffuse venous malformations of the upper extremity (Bockenheimer disease): diagnosis and management. Plast Reconstr Surg 146: 1317-1324. doi:10.1097/PRS.0000000000007365

Boscolo E, Limaye N, Huang L, Kang KT, Soblet J, Uebelhoer M, Mendola A, Natynki M, Seront E, Dupont S, et al. 2015. Rapamycin improves TIE2-mutated venous malformation in murine model and human subjects. J Clin Invest 125: 3491-3504. doi:10.1172/JCl76004

Dekeuleneer V, Seront E, Van Damme A, Boon LM, Vikkula M. 2020. Theranostic advances in vascular malformations. J Invest Dermatol 140: 756-763. doi:10.1016/j.jid.2019.10.001

Du Z, Zheng JW, Zhang ZY, Wang YA. 2017. Review of the endothelial pathogenic mechanism of TIE2-related venous malformation. J Vasc Surg Venous Lymphat Disord 5: 740-748. doi:10.1016/j.jvsv.2017.05.001

Hammer J, Seront E, Duez S, Dupont S, Van Damme A, Schmitz S, Hoyoux C, Chopinet C, Clapuyt P, Hammer $F$, et al. 2018. Sirolimus is efficacious in treatment for extensive and/or complex slow-flow vascular malformations: a monocentric prospective phase II study. Orphanet J Rare Dis 13: 191. doi:10.1186/s13023-0180934-z

Kubiena HF, Liang MG, Mulliken JB. 2006. Genuine diffuse phlebectasia of Bockenheimer: dissection of an eponym. Pediatr Dermatol 23: 294-297. doi:10.1111/j.1525-1470.2006.00239.x

Limaye N, Wouters V, Uebelhoer M, Tuominen M, Wirkkala R, Mulliken JB, Eklund L, Boon LM, Vikkula M. 2009. Somatic mutations in angiopoietin receptor gene TEK cause solitary and multiple sporadic venous malformations. Nat Genet 41: 118-124. doi:10.1038/ng.272

Limaye N, Kangas J, Mendola A, Godfraind C, Schlögel MJ, Helaers R, Eklund L, Boon L, Vikkula M. 2015. Somatic activating PIK3CA mutations cause venous malformation. Am J Hum Genet 97: 914-921. doi:10.1016/j.ajhg.2015.11.011

Mulliken JB, Glowacki J. 1982. Hemangiomas and vascular malformations in infants and children: a classification based on endothelial characteristics. Plast Reconstr Surg 69: 412-420. doi:10.1097/00006534198203000-00002

Nätynki M, Kangas J, Miinalainen I, Sormunen R, Pietilä R, Soblet J, Boon LM, Vikkula M, Limaye N, Eklund L. 2015. Common and specific effects of TIE2 mutations causing venous malformations. Hum Mol Genet 24: 6374-6389. doi:10.1093/hmg/ddv349

Salloum R, Fox CE, Alvarez-Allende CR, Hammill AM, Dasgupta R, Dickie BH, Mobberley-Schuman P, Wentzel MS, Chute C, Kaul A, et al. 2016. Response of blue rubber bleb nevus syndrome to sirolimus treatment. Pediatr Blood Cancer 63: 1911-1914. doi:10.1002/pbc.26049

Soblet J, Kangas J, Nätynki M, Mendola A, Helaers R, Uebelhoer M, Kaakinen M, Cordisco M, Dompmartin A, Enjolras O, et al. 2017. Blue rubber bleb nevus (BRBN) syndrome is caused by somatic TEK (TIE2) mutations. J Invest Dermatol 137: 207-216. doi:10.1016/j.jid.2016.07.034

Vikkula M, Boon LM, Carraway KL, Calvert JT, Diamonti AJ, Goumnerov B, Pasyk KA, Marchuk DA, Warman ML, Cantley LC, et al. 1996. Vascular dysmorphogenesis caused by an activating mutation in the receptor tyrosine kinase TIE2. Cell 87: 1181-1190. doi:10.1016/S0092-8674(00)81814-0 


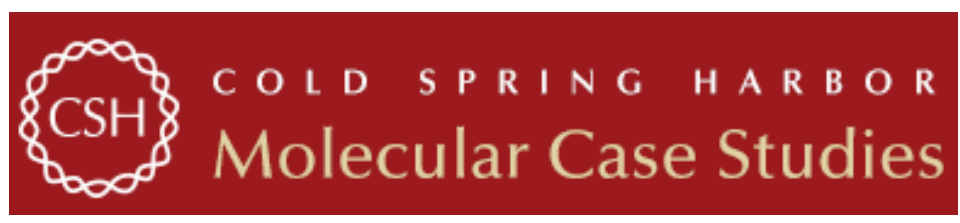

\section{Bockenheimer disease is associated with a TEK variant}

Christopher L. Sudduth, Dennis J. Konczyk, Patrick J. Smits, et al.

Cold Spring Harb Mol Case Stud 2021, 7: a006119 originally published online October 14, 2021

Access the most recent version at doi: $10.1101 / \mathrm{mcs} . a 006119$

\begin{tabular}{cl}
\hline License & $\begin{array}{l}\text { This article is distributed under the terms of the Creative Commons } \\
\text { Attribution-NonCommercial License, which permits reuse and redistribution, except } \\
\text { for commercial purposes, provided that the original author and source are credited. } \\
\text { Email Alerting } \\
\text { Service }\end{array}$ \\
$\begin{array}{l}\text { Receive free email alerts when new articles cite this article - sign up in the box at the } \\
\text { top right corner of the article or click here. }\end{array}$ \\
\hline
\end{tabular}

